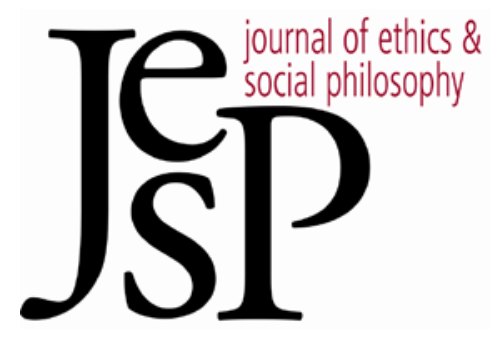

Normative Pluralism Worthy of the Name Is False

by Spencer CASE

JoURNAL OF ETHICS \&SOCIAL PHILOSOPHY

Vol. 11, No. 1 | NOVEMBER 2016

URL: WWW.JESP.ORG

COPYRIGHT (C SPENCER CASE 2016 


\title{
Normative Pluralism Worthy of the Name Is False
}

\author{
Spencer Case
}

$\mathrm{N}$ ORMATIVE PLURALISM IS THE VIEW that practical reason consists in an irreducible plurality of normative domains, that these domains sometimes issue conflicting recommendations, and that, when this happens, there is never any one thing that one ought simpliciter to do. Suppose that self-interest and morality are two normative domains. It might then be true that reporting an unethical boss to the authorities would be morally recommended, but that not reporting him to avoid reprisals would be self-interestedly recommended. Knowing this much, you might think that you do not know the most important normative fact: what you just plain ought to do. If normative pluralism is true, then there would remain no further normative fact of this kind to be uncovered. Morally you should do one thing; self-interestedly you should do another - there things bottom out.

Here I argue against this view. All versions of normative pluralism can be classified as being either unrestricted or restricted. Unrestricted pluralism maintains that all coherent standards are reason-generating normative domains whereas restricted pluralism maintains that only some are. We shall see that unrestricted pluralism, depending on how it is cashed out, is either nihilism about practical reason or else it is subjectivism. Neither view is consistent with normative pluralism; hence, pluralism must be restricted. Restricted pluralism, however, faces two problems. The first stems from the question: "Why is it that some standards are normative domains while others are not?" The question seems to demand an answer, but it is hard to give any answer without appealing to considerations that imply facts about what we ought simpliciter to do. Second, restricted pluralism leads to absurdity in a three-way dilemma that I will describe. So we have good reason to think restricted pluralism is false, too.

Since my concern here is presenting and defending my argument against pluralism, I will not respond to the arguments that have already been given in its favor. ${ }^{1}$

\section{What Is Normative Pluralism?}

A number of philosophers, including David Copp (1997, 2007, 2009), Michael Smith (1994: 95), Evan Tiffany (2007), Matthias Sagdahl (2014) and Derek Baker (forthcoming), have recently defended versions of what I am calling "normative pluralism." Here are a few presentations of this view.

1 Probably the most cited and influential argument for pluralism is presented by Copp (1997). See McLeod (2001) and Dorsey (2013) for responses. Ruth Chang provides an overview of the influential argument from notable-nominal comparisons against pluralism, which I will not discuss here, in (1997: 1-34). 
Copp, in his seminal paper, "The Ring of Gyges: Overridingness and the Unity of Reason," writes that:

I will be defending the position that neither morality nor self-interest overrides the other, that there simply are verdicts and reasons of these different kinds, and that there is never an overall verdict as to which action is required simpliciter in situations where moral reasons and reasons of self-interest conflict. ... In my view, there is no standpoint that can claim normative priority over all other normative standpoints and render a definitive verdict on the relative significance of moral and selfinterested reasons. That is, in cases of conflict between kinds of reasons, there is no fact as to what a person ought simpliciter to do (1997: 86-87).

\section{Likewise, Tiffany writes:}

It is a feature of the view I call deflationary normative pluralism that, strictly speaking, any proposition of the form "A has a reason to $\phi$ in $\mathrm{C}$ " expresses an incomplete thought insofar as it fails to specify the type of reason in question. Thus we can only ask, e.g., "Is there really a moral reason why I should act morally?" or "Is there really a self-interested reason why I should act morally?" If right, then both the authority and the supremacy questions are illegitimate because neither can be formulated in a way that does not employ the problematic concept of an unqualified reason (2007: 33).

\section{Sagdahl defends that view that:}

practical normativity is not a unified domain, but that it rather consists of several incommensurable domains, such as morality and prudence. With this idea in mind, we can think that there are moral reasons and prudential reasons, but that there are no plain reasons (no reasons simpliciter). Similarly, we can think that while there are things one morally ought to do, and things that one prudentially ought to do, there are no things we just plain ought to do. We can call an idea like this normative pluralism (2014: 405).

There are important differences between these thinkers, some of which we will discuss in due time. Nonetheless, each assents to the following three claims, the conjunction of which is normative pluralism:

1. Source pluralism: There exists an irreducible plurality of normative domains, which issue oughts of distinct kinds. ${ }^{2}$

2. Conflict. It is possible for two or more of these domains to issue conflicting recommendations on what to do (i.e., "X-ly one ought to $\phi$, Y-ly one ought not to $\phi$," where $\mathrm{X}$ and $\mathrm{Y}$ are two normative domains). ${ }^{3}$

2 Note that irreducibility does not by itself imply incommensurability. A source pluralist may think that moral obligations normatively override self-interest, as Sarah Stroud does (1998), or that strong reasons of self-interest can override moral reasons, a view endorsed by Michael Slote (1983: 119-21) and Philippa Foot (2002: 181-88).

3 One way would be to hold that two domains are in conflict if and only if they issue incompatible requirements or obligations. According to scalar consequentialism, a view championed by Alastair Norcross (2006), morality issues no requirements, but only reasons of vary- 
3. No authoritative adjudication: There is no "all things considered" domain capable of issuing recommendations about what one ought simpliciter to do; hence, no authority exists that is capable of adjudicating disputes between normative domains.

To say that one ought simpliciter to do something is not to say that one ought to do something according-to-yet-another-norm, to borrow an expression from Stan Husi (2013: 424). It is to say that one ought from a stance that is comprehensive, giving due weight to all reasons issued by the subordinate domains, whose recommendations are authoritative and unrivaled, and so normative in the most robust sense. Copp has called this overarching normative domain "Reason" (with a capital "R") and "Reason-as-such" (1997: 94). Although I find none of the many proposed labels completely satisfactory, I will follow Owen McLeod in calling it the "all things considered" domain, which best captures its comprehensiveness and is suggestive of its authority (2001: 269-81).4

Many add a fourth claim. Copp's concludes that "the idea of a standard of Reason-as-such is incoherent" (1997: 103).5 Tiffany, as we have seen, writes that "any proposition of the form "A has a reason to $\phi$ in $C$ " expresses an incomplete thought insofar as it fails to specify the type of reason in question" (2007: 233). In the same passage, he calls the concept of an unqualified reason "problematic." Dorsey, who rejects pluralism, notes that one form of it "is a product of the fact that we cannot make sense of an allthings-considered standpoint" (2013: 16). So many, and perhaps most, pluralists accept the following:

4. Semantic pluralism: Not only is there no "all things considered" domain to adjudicate disputes between first-order normative domains, but the very concept or idea of a domain that can issue verdicts that we ought simpliciter to follow is incoherent or confused.

If semantic pluralism is true, then normative pluralism is true. One can, however, accept normative pluralism without accepting semantic pluralism, just as one can be an atheist without thinking the idea of God is incoherent. Similarly, just as a proof of God's existence would refute the notion that the concept of God is incoherent, a refutation of normative pluralism would ipso

ing strengths depending upon the consequences they produce. One could construct counterpart scalar views of almost any other normative domain. It seems to make sense to say that two scalar normative domains, $\mathrm{X}$ and $\mathrm{Y}$, conflict when one X-ly has good reason to $\phi$, but Y-ly one has good reason not to $\phi$. I will speak of a domain's "recommending," rather than "requiring," an action in order to canvas this possibility.

4 The primary drawback to this label is ambiguity. "All things" can be considered in the light of a variety of concerns, e.g., morally, or prudentially. By all things considered, I mean all reasons given their due normative weight simpliciter.

5 See n. 3 for a brief discussion of the difference between structural and substantive/permissive pluralism. 
facto refute semantic pluralism. If we can establish that there is an all-thingsconsidered domain, whose verdicts tell us what we ought simpliciter to do, then the idea of that domain, and ought simpliciter, must be coherent. Because I am arguing for exactly that, I will say no more about semantic pluralism.

\section{Unrestricted Pluralism}

Pluralism is unrestricted if all coherent standards are normative domains. Pluralism is restricted just in case at least some coherent standards fail to constitute normative domains in virtue of their content. Here I claim that reasons are inherently comparative. In order for something to be a reason, it must be the case that it is possible for it to make a difference to our normative situation relative to the other options in at least some instances. If that is right, then any metaethical view that counts every coherent standard as a normative domain is ultimately inconsistent with source pluralism and so cannot be a form of normative pluralism. It follows that normative pluralism must be restricted.

To be coherent, a standard must be logically consistent and satisfy a few other formal criteria. A coherent standard cannot demand the impossible, nor can it be tailored to specific actions or individuals (e.g., the standard of "Fred walking his dog in Central Park on Saturday, October 15, 2016"). For the unrestricted pluralist, all coherent standards, however ridiculous or repugnant, are normative domains. Although unrestricted pluralism is not a common view, it appears to be held by Tiffany and a few other philosophers. ${ }^{6}$ For Tiffany, something is a normative domain (or a "reasongenerating standpoint," in Tiffany's terminology) if and only if:

There is some well-defined aim (e.g., intrinsic-desire-satisfaction), institutional framework (e.g., positive law), or standard of value (e.g., aesthetic value) relative to which considerations may be judged as standing in some normative relation to action (e.g., favouring, defeating, enabling) (2007: 255).

Tiffany does not specify what he means by a "well-defined aim" or what it means for there to be "some standard of value," but his willingness to consider reason-giving standpoints such as an "absurdism standpoint," (2007: 248) as well as domains of "anarchy" and "rudeness" (2007: 258-59), makes it clear that he intends both to be very wide in scope. He never provides an example of a standard that fails to be a normative domain in virtue of its content. The way he contrasts his own "deflationary normative pluralism" with Copp's "grounded" pluralism, about which more in due time, further sup-

${ }^{6}$ Derek Baker is developing a similar view, but his work is still in manuscript form. Husi, although he describes his view as "meta-normative reasons skepticism" also seems to endorse unrestricted pluralism (2013). In private conversations I have also heard this view endorsed by several philosophers, generally with naturalistic tendencies, who have not published on the topic. 
ports the interpretation that he is what I am calling an "unrestricted pluralist" (2007: 253-59). So I will interpret Tiffany's "deflationary normative pluralism" as being equivalent to what I am calling "unrestricted pluralism."

One immediate concern one might have about unrestricted pluralism is that some standards do not seem to be normative domains. Dorsey's "Constitution of the Satanic Grave Robbers Society" is as colorful an example as any (2013: 118). If unrestricted pluralism is true, then we have reasons to follow the Constitution of the Satanic Grave Robbers Society - reasons of the Constitution-of-the-Satanic-Grave-Robbers-Society sort! Many will take this to be a reductio ad absurdum against unrestricted pluralism. The unrestricted pluralist, however, has a ready reply: most of us erroneously suppose that that there are no reasons of the Constitution-of-the-Satanic-Grave-RobbersSociety sort because most people are not partisan toward that domain. As Tiffany explains:

By denying the supremacy of morality, or any other standpoint for that matter, normative pluralism does not commit one to nonpartisanship. Just as one may be a partisan supporter of the Canucks over the Maple Leafs - perhaps even seeing support for the Leafs as a character flaw, admittedly non-culpable for those raised in greater Toronto - without thinking that there is some deep metaphysical truth backing up one's partisanship; so too can one be similarly partisan toward, e.g., morality, prudence, or authenticity (2007: 244-45).

A non-pluralist might retort that the Satanist, interrogated about why he adheres to these standards, probably would not appeal to Constitution-ofthe-Satanic-Grave-Robbers-Society reasons. Rather, he would be expected to say "because I have taken the blood oath," or "because Satan is lord," or "because it is better to rule in hell than to serve in heaven" - answers that concede that the society's standards are not foundational. Perhaps this just shows that we are really imagining an interlocutor with partisanships like our own. Can we do otherwise, though? Plausibly, our partisanships constrain what sorts of considerations we can take to be reasons. Do they also constrain which of the many standards are normatively relevant to us? In other words: does a person's partisanship affect what normative reasons he has?

Tiffany seems to want to have it both ways on this question. He describes our partisanships as having "deliberative authority" for us. Although "authority" implies normative significance, Tiffany defines "deliberative authority" in apparently nonnormative, psychological terms: "a normative standpoint has deliberative authority for an agent if that agent is disposed to treat the standpoint as a source of contributory reasons that are relevant to her practical deliberations" (2007: 248). One can of course be disposed to treat a standpoint's recommendations as being normatively significant without their actually being so. Tiffany says that deliberative authority is "merely subjective," whereas "the concept of genuine deliberative weight must refer to an objective property" (2007: 248). 
An unrestricted pluralist could answer the question either way. Let us consider each in turn, starting with what I take to be Tiffany's considered view: partisanship is a normatively irrelevant, purely psychological matter. In that case, one's reasons to act in accordance with whatever standard seems most ridiculous or reprehensible to you are normatively on a par with one's reasons to act in accord with any other set of standards. If all coherent standards are normative domains, then every domain has an equal and opposite domain (except perhaps the domain of "acting coherently"). We have seen Tiffany's own examples of "anarchy" and "rudeness," opposites of lawfulness and etiquette, respectively. We can add ugliness, self-destruction and immorality to the list of hitherto neglected domains.

I claim that such a view is tantamount to nihilism about practical reason. That may be a surprising thing to say. Nihilism about practical reason is the view that one never has reason to do anything; unrestricted pluralism entails that one always has an unlimited number of reasons on every side of every decision. Superficially, it seems as though no two views could be more different. And yet both agree that nothing makes a difference to our normative situation - indeed, nothing could make such a difference. Either we have no reasons counting in favor of anything, or we have an infinite number of reasons, generated by an indefinite number of standards, pulling in every direction. So in some sense all options are on a par, regardless of what circumstances may obtain.

Can normativity be extended this far, even in principle? Consider an analogy with rank. When Burma sought independence from British colonialism, activists and fighters subversively called each other "Thakin," or "master," a title of respect that the occupying British officers insisted on being called (Steinberg et al., 2016). If everyone is Thakin, the revolutionaries understood, then no one is. In a perfectly egalitarian society where everyone is called Thakin, the word must be shorn of its original meaning in something like the way that the revolutionaries intended. Likewise, I submit, if all coherent standards are normative domains, then the result seems to be that none are. A normative domain's recommendations must deserve our respect, and must possess authority over the recommendations of competing standards at least some of the time. I cannot make sense of the claim that all standards are normative domains any more than I can make sense of the claim that everyone is properly addressed as Thakin, if this is truly a title of distinction. The only sense I can make of the suggestion that all standards are normative domains is that no standards are really normative domains; hence unrestricted pluralism, so understood, collapses into nihilism. ${ }^{7}$

Suppose now that the unrestricted pluralist answers that partisanship does make a normative difference. Plausibly, only the domains toward which I am

7 There is no upper limit conceptually on how many of our decisions might be normative ties, with reasons equally balanced on both sides. But I insist on the modal claim: in order for something to be a reason, there must be a possibility of its making a difference in some set of circumstances, even if it never happens in any actual set of circumstances. 
partisan are normatively significant for me. ${ }^{8}$ This view takes seriously the normative implications of Tiffany's term "deliberative authority" and accommodates the intuition that there are some standards, like the Constitution of the Satanic Grave Robbers Society, that give us no reasons for action. The resulting view, however, is subjectivism about practical reason. One's partisanship cannot be, per unrestricted pluralism, a rational response to any objective features of the standards of which one is a partisan, but some sort of nonrational pro-attitude, or collection of pro-attitudes. Tiffany's sports analogy suggests as much. Partisanship, except in the cases of radical egoists, saints and fanatics of various sorts, will be divided among several domains whose recommendations sometimes conflict. Such dilemmas would seem to be resolvable only through the formation of more specified partisanships.

Let us take stock. I have argued that unrestricted pluralism can be spelled out to make partisanship normatively irrelevant or normatively relevant. Spelled out in the first way, it amounts to, and may actually be, nihilism about practical reason. Spelled out in the second way, it amounts to normative subjectivism. Neither view can be squared with normative pluralism. Nihilism about practical reason is inconsistent with the idea that there are any normative domains, let alone a plurality of them. Subjectivism cannot be accused of being nihilism in drag, but it is a form of normative monism because one's partisanship (i.e., one's subjective mental states) alone determines what standards are authoritative for one. If normative pluralism is to be both normative and pluralistic, then unrestricted pluralism must be restricted.

\section{Restricted Pluralism}

Pluralism is restricted just in case it holds that there is at least one coherent standard that is not a normative domain. The proponent of this form of pluralism wants to separate the wheat from the chaff and insist that content as well as coherence are relevant to a standard's normative significance. Copp, for example, does not want "moon-love reasons" to be on a par with reasons of morality or self-interest (2007: 110). Tiffany objects that it is unclear whether the standard of "moon-love" is a coherent standard in the first place (2007: 255). I think Copp has in mind something like "the standard according to which those actions are best that most express love for the moon."

\footnotetext{
${ }^{8}$ Is there space for an intermediate position distinct from subjectivism? We could imagine that all coherent standards constitute normative domains, but that one's partisanship causes some to be more important than others. I do not think that such a position is workable, however. It seems, first of all, that we owe the Constitution of the Satanic Grave Robbers Society no role at all in our practical reasoning. Second, the reasons generated by the myriad domains toward which we are nonpartisans would essentially cancel each other out. What would really be carrying the weight would be the domains toward which we are partisan. And so any such compromise must in the end boil down to subjectivism or its practical equivalent.
} 
This is apparently coherent. It nonetheless does not seem like a standard that we are obliged to take seriously, as Tiffany acknowledges.

Although, in principle, restricted pluralism could be almost as inclusive as unrestricted pluralism, in practice, restricted pluralists allow for no more than a few domains. This parsimony keeps the view more intuitively appealing than unrestricted pluralism, at least at first blush. Morality and selfinterest (sometimes called "prudence") are the most commonly proposed domains. Others include aesthetics, etiquette, perfectionism and legality. Occasionally, it will be convenient to speak of other standards as if they were normative domains. Stroud considers the case of "social-climbing reasons" that is, reasons instrumental to the goal of moving up the social ladder in a context in which doing this seems unlikely to do much good. Such reasons, she says, are not "genuine reasons for action" but only domain-relative reasons, or "D-reasons" (1998: 172-73).

Stroud equates genuine reasons for action with reasons simpliciter. Obviously, no restricted pluralist could differentiate D-reasons from the genuine article on that basis, at least without making "genuine reasons for action" an empty category. She could, however, say that "genuine reasons for action" are those that are generated by one of the few normative domains, whereas D-reasons have no normative force of their own, although they may have instrumental value. Plausible examples of the latter include financial reasons, political reasons and, yes, social-climbing reasons. Reasons relative to standards that do nothing to further the goals of any normative domains, plausibly including the Constitution of the Satanic Grave Robbers Society, can be referred to as "mere D-reasons."

Many have thought restricted pluralism to have been refuted by the socalled "argument from notable-nominal comparisons," discussed by Ruth Chang (1997: 14-17), Derek Parfit (2011: 135), Dale Dorsey (2013: 119-24), Tim Scanlon (1998: 235) and others. ${ }^{9}$ This argument features an appeal to intuition. We are asked to imagine a choice between a very small good in one domain (usually self-interest) at the expense of a tremendous cost in another domain (usually morality). To borrow a famous example from Peter Singer (1971; 2010: xi-5), one might have to get one's clothes wet to rescue a drowning child. We want to say more about this case than that "one morally ought to rescue the child, but self-interestedly ought not to rescue the child." We want to say something like "one just plain ought to do what you morally

\footnotetext{
9 In principle, the argument could be directed against unrestricted pluralism. It would, however, be much less dialectically effective against an unrestricted pluralist because the argument relies on intuitions of a kind that the unrestricted pluralist is happy to disregard or explain away. Someone who is comfortable positing Constitution-of-the-Satanic-GraveRobbers-Society reasons, though it seems for all the world that there are no such things, will not be troubled in simply biting the bullet in this case, too. As far as I am aware, everyone who has pressed the argument from notable-nominal comparisons has pressed it against restricted pluralism.
} 
ought to do." And so we are pushed toward positing an all-things-considered domain capable of issuing supremely authoritative "oughts" like this.

Perhaps we should not be so confident that this argument succeeds. Sagdahl has recently advanced a compelling response to this objection that allows the restricted pluralist to accommodate the relevant intuition. He claims that "all things considered ought" need not be interpreted as an appeal to the verdict of an all-things-considered domain:

Instead, "ought all things considered" can be given a quantificational interpretation. Whenever standpoints are in agreement, we can make a universal quantification over them. Suppose that you ought to F both from the moral and prudential standpoint, so that you both morally and prudentially ought to F. If these are the only relevant standpoints, we can say truly that from all normative standpoints, you ought to F. No intertype commensuration of reasons is involved in reaching this conclusion (2014: 410-11).

This kind of response would not work if the various domains did not generally concur in their recommendations, but concurrence seems plausible at least in the cases of morality and self-interest. Committing moral atrocities does not usually advance one's self-interest. A policy of promoting one's own self-interest would rule out committing atrocities, especially when the expected payoff is trivial. Philosophers can stipulate that no bad consequences (self-interestedly speaking) will result from a particular instance of morally bad behavior, but our intuitions may not keep up with unrealistic stipulations. So the pluralist can say that we have good reason in every domain to adopt a policy of always choosing the notable good in notable-nominal cases. Our knowledge of this general rule renders unreliable our intuitions about weird cases.

A couple of points of criticism are in order. First, note the more normative domains the pluralist posits beyond morality and self-interest, the less likely that they will generally concur. Sagdahl's reply works best as a defense of dualism between morality and self-interest; it is likely to be less persuasive as a defense of other forms of pluralism that include more domains than these two. What is more, the non-pluralist can modify the argument so that we are invited to consider choices between two notable goods, one of which seems much more notable than the other. ${ }^{10}$ Nonetheless, if Sagdahl has not put paid to the argument, he has at least shown that it may not be the decisive refutation of restricted pluralism that many have thought it to be. In

10 Sagdahl, anticipating this criticism, considers a case in which someone must either pay $\$ 200,000$ or allow all Falklanders to die. The prospect of losing that sum of money, for the average person, can hardly be considered a "nominal" loss, and so it is plausible that morality and self-interest really diverge in this case. And yet many will insist that it is unreasonable, all things considered, to allow all Falklanders to die in order to keep the money. Sagdahl replies to his own objection in part by saying that, given the costs at stake, it is plausible to think that either action may be rationally acceptable (2014: 420-24). But what if we lower the cost to $\$ 3,000$ ? 
what follows, I present two new arguments against restricted pluralism that I think are more decisive, especially when considered jointly.

\subsection{The Sorting Problem}

According to restricted pluralism, not all coherent standards are normatively on a par. What differentiates them? What determines why some standards are to be taken seriously, but not others? In principle, a restricted pluralist could say that this is a matter of brute fact, and there is nothing to be said about why morality, but not the Constitution of the Satanic Grave Robbers Society, is a normative domain. Intuitively, though, that some standards deserve to be respected, and others do not, cries out for an explanation. Copp, a restricted pluralist, recognizes this and attempts to provide one. What differentiates the reason-generating standpoints from the non-reason-generating standpoints, according to Copp, is that reason-giving standpoints are "devices" suited to ameliorate some "problem of normative governance" facing humanity. Copp writes that:

the capacity of humans to deal successfully with these problems depends on their subscribing to systems of norms or standards. Our subscription to these systems enables us to deal with the relevant problems. This is the basic fact that underlies all normativity. For example, the function of morality is to ameliorate the problem of sociality. The normative systems that have a relevant normative status, according to pluralist-teleology, are abstract systems of rules that, when subscribed to and complied with by enough of the people in their scope, enable us to deal with such problems. The function of the various normative systems of this sort that play characteristic roles in human life is to enable us to cope with these problems (2009: 26).

\section{He continues:}

We need the cooperation of others to achieve what we value, no matter what we value, within at least a wide range of things we might value. We also need the existence of a minimum level of peace and stability in society. We need to live peacefully and cooperatively together (2009: 27).

Other alleged problems of normative governance include the problems of autonomy and politeness, and the epistemic problem, which are answered by the normative domains of prudence, etiquette and epistemic rationality, respectively (2009: 27-28). Tiffany is rightly unimpressed by this response, which he perceives to be a relocation of the problem: ${ }^{11}$

But, to my mind, this simply pushes the question back a level; for now we must know why facilitation of pleasing and comfortable interactions is a genuine problem of normative governance but facilitation of unpleasant and confrontational in-

11 Tiffany's response to Copp (2009) is available in the online (2013) version of the (2007) article. 
teractions is not. While most of us value security and may accept a system of law as an authoritative device for securing that security, one can imagine a group of anarchists who despise security and seek a normative system that solves the problem of anarchy (2007: 258-59).

We can press Tiffany's point further by focusing on the question of what, exactly, constitutes a "problem" or a "need" in this context. Copp could cash these out in purely descriptive terms, which would be consistent with his naturalism. For example, a "need" could be whatever most human beings strongly desire, and a "problem" could be whatever gives most human beings a sense of anxiety. But if these are understood in purely descriptive terms, reducible to complexes of psychological states, then it is mysterious why they, as opposed to other bundles of descriptive properties, should be normatively foundational. It is mysterious why they, as opposed to something else, should determine what standards are normative domains. Copp's purported solution thus leaves the sorting problem unresolved.

If, on the other hand, "problems" and "needs" are understood in normative terms, then we are entitled to ask the pluralist: "which normative terms?" To understand them within the framework of any one domain results in the appearance of self-selection - one domain simply declaring its own concerns to be the most important. For example, suppose the pluralist were to say that these needs morally ought to be met by those who can meet them, and these problems ought morally to be solved by those who can solve them. Why should we defer to morality's standards to explain which problems, and which needs, are foundational for normativity? Could we not equally well defer to the standards of self-interest, or the Satanic Grave Robbers Society, or what have you, to tell us what our problems and needs are?

If the "ought" implicated in Copp's "problems" and "needs" cannot be internal to any one domain, then could it perhaps be shared by many domains? Perhaps the pluralist can borrow a page from Sagdahl and say that the "problems" and "needs" that matter are the ones that we "all things considered ought" to care about (meaning, on Sagdahl's account, that all normative domains concur on their importance). But we can just as well ask, "Which coalition of standards determines which things one 'all things considered ought' to do?" Morality, self-interest, aesthetics, etiquette and legality might concur that one should do A, but their evil twins, immorality, selfdestruction, ugliness and rudeness, might concur that one should not do A. If we opt for the former, we allow one coalition to sort itself into the good pile without having any special authority to do so. So the same problem reoccurs.

None of this would be very disconcerting to the pluralist if the same problem bedeviled the non-pluralist: "a problem for all is a problem for none." The non-pluralist can say that we ought simpliciter to care about only some oughts (McLeod (2001: 274-75)). But because ought simpliciter has properties that the various rival oughts of restricted pluralism are not claimed to have, no self-selection problem arises here. Ought simpliciter is by defini- 
tion comprehensive and normatively authoritative, and therefore peerless. Deference to the one kind of "ought" that has these properties over one that does not cannot be called arbitrary. Of course, we might think it a problem to determine what things we ought simpliciter to do, but that is a different problem, and one not unique to ought simpliciter. We might equally well ask why we morally ought to do the things we morally ought to do, for example.

Perhaps some other solution for the sorting problem will be proposed on behalf of the restricted pluralist. Nothing, however, seems promising, and so I conclude that it remains an outstanding problem for the restricted pluralist. Unfortunately, restricted pluralism faces an even more serious objection to which I now turn.

\subsection{The Concurrence Argument}

Philosophers who have investigated pluralism have tended to focus on wrenching cases of conflict between the reasons of two domains, where the stakes are high on both sides. Sidgwick was famously unsettled by the implications of "the rarer cases of a recognized conflict between self-interest and duty" (Sidgwick (1963/1874: 508)). Thomas Nagel makes it clear in "The Fragmentation of Value" that conflict cases are his main concern (1979: 12832). Copp, likewise, specifically addresses "situations where moral reasons and reasons of self-interest conflict" (2007: 285). David Brink suggests that harmony among the domains of practical reason would solve or ameliorate the challenges posed by pluralism (1997: 291). The fixation on hard cases of conflict has had one unfortunate upshot: philosophers have paid scant attention to concurrent cases, in which the recommendations of normative domains agree, or partially agree, on what course of action is best (or at least on what range of options are among the best). Here I aim to show that we can learn something about normative pluralism by thinking about concurrent cases.

Copp (1997) retells the story of Gyges that Glaucon tells Socrates in The Republic (Plato 1997: 359c-61d). Gyges, a shepherd in the service of the king of Lydia, discovers a ring with the power to make him invisible. Gyges uses it the way Glaucon thinks we all would: to live a self-indulgent life, unencumbered by morality. Gyges has an affair with the queen, then conspires to murder her husband and make himself king. Copp describes Gyges as having two options: living a morally good but self-interestedly bad life as a shepherd, or living a morally bankrupt life but "living well" as king. Gyges, on Copp's telling, is in a position in which he is, in Thomas Reid's words, "reduced to this miserable dilemma, whether it is be best to be a fool or a knave" (1969/1788: 257).

Pluralism accommodates widely held intuitions about these cases. It seems that in such scenarios there is nothing to do but make a nonrational leap to one side or the other, to make what Tiffany calls an "agential choice" (2007: 244). But I think that non-pluralism can also satisfactorily accommodate our intuitions about such cases. We can, without accepting pluralism, 
think that we are occasionally faced with ties at the highest normative level, so that we ought simpliciter to do either A or B, but not one of them in particular. ${ }^{12}$ The non-pluralist can also say that it is generally hard to know what to do when the stakes are high on either side of some decision, even if all the reasons in play are of the same kind. We do not, when confronted with intradomain hard cases, assume that there is no best option by the standards of whatever domain it is we are considering. Neither should we in inter-domain hard cases leap to the conclusion that there is no option that we ought simpliciter to do.

So non-pluralists can deal well enough with the "best case" for pluralism. On the other hand, there is a different dilemma that pluralism cannot deal with very well. Consider a modification of the Gyges story in which Gyges has a third option that allows him both to live well and to live morally. Suppose that the current king plans to abdicate soon, but has not named a successor. The Lydians have a less-than-venerable tradition, when this happens, of choosing their leaders based upon their entertainment skills, rather than their ability to govern (a practice not unknown in modern societies). So, fortunately for Gyges, the next king is to be chosen by a public magic trick contest. (Naturally, no one thought to include a rule disqualifying those possessing genuinely magic trinkets.) Gyges has an easy and legitimate path to the throne..$^{13}$

Gyges' decision is now between three options. As with the original story, choice one is to remain a shepherd and choice two is to seize power illegitimately. (Maybe he coerces the king into naming him the successor, obviating any need for any public magic contest.) Choice three is to compete in the magic contest and become king legitimately. This option is just as good for Gyges as seizing the throne through force or subterfuge would be. It is morally good, too, since being a king (let us say) is honorable work, though not morally better than remaining a shepherd. After all, given how the successor to the king is to be chosen, Gyges has no reason to believe that he is either better or worse at governing than the average competitor.

12 If ties became too widespread, though, we would end up with Dorsey's "substantive pluralism" (2013: 117-27).

13 I thank Neil Sinhababu for helping me fine-tune this example. 
Table 1. The Gyges Concurrent Case ${ }^{14}$

\begin{tabular}{|l|c|c|c|}
\hline & 1. Remain a shepherd & 2. Use ring wickedly & 3. Use ring morally \\
\hline Self-interest & Bad $(-1,000)$ & Good $(+1,000)$ & Good $(+1,000)$ \\
\hline Morality & Good $(+1,000)$ & $\operatorname{Bad}(-1,000)$ & Good $(+1,000)$ \\
\hline
\end{tabular}

Among these choices, I suspect that you would not hesitate to recommend 3, the course of action that is unique in being both as self-interestedly good as any other option, and as morally good as any other option. You might even want to say that Gyges ought to choose 3. We are stipulating, along with Copp, that self-interest and morality are the only domains in play. The "ought" by which we ought to choose 3 does not seem to be either; it seems Gyges ought simpliciter to choose 3, a result that is inconsistent with restricted pluralism. ${ }^{15}$ I call this the "concurrence argument." The pluralist can respond either by "biting the bullet" - rejecting the intuition that Gyges ought to choose 3 - or by trying to explain how restricted pluralism can accommodate the "ought" in play. Let us consider each in turn. ${ }^{16}$

First is the option to reject the intuition. Morally, Gyges ought to choose 1 or 3; self-interestedly, Gyges ought to choose 2 or 3. The pluralist could assent to such propositions as " 3 is the only option that is good according to both morality and self-interest" or " 3 is the only option that does not have one strike against it, in some domain or other." Gyges would probably infer from these statements that he ought to choose 3, but the pluralist would have to insist that no such implications follow. Given the force of the intuitions to the contrary, it seems that the pluralist needs recourse to some kind of error theory. Again it seems that the pluralist would do best to appeal to partisanship, understood in a nonnormative way. This reply might go:

Sure, it appears to you that Gyges ought simpliciter to choose 3. But that is only because you are partisan to morality. We can imagine an amoralist who only cares about self-interest; he would be completely indifferent between options 2 and 3 . And so your strong intuition that Gyges ought to choose 3 can be assumed to be derivative from your preferences, not from any normative considerations.

${ }^{14}$ The numbers are meant to signify units of whatever kind of reason is commensurate within the domain, not all-things-considered reasons. More complicated convergence cases can be constructed that involve many different domains. Imagine for the sake of simplicity that all three options are tied in every other domain.

15 The argument could not as successfully be run against unrestricted pluralism because, for the restricted pluralist, there will be usually ignored domains on the other side - immorality and self-destruction would concur that 3 is the worst thing that Gyges could do. That might seem implausible, but that objection takes us back to the discussion in section 2 .

16 Henceforth, unless I explicitly say otherwise, I mean the "restricted pluralist." 
The problem with that reply is that we are supposed to be assuming the truth of restricted pluralism, according to which there is a plurality of normative domains. For the sake of giving a vivid example, it is necessary to construct the concurrent case as occurring between two particular domains. I chose morality and self-interest because they are the least controversial. The amoralist is either someone who does not consider morality to be a normative domain, or else someone who recognizes that it is a normative domain, but who refuses to take those reasons into consideration. In the first case, he just has not accepted what I am stipulating, and what must be stipulated for any reductio ad absurdum against restricted pluralism, i.e., that there is an irreducible plurality of different normative domains of which self-interest is just one. In the second case, he is being irrational. What, after all, is more paradigmatically irrational than refusing to take known reasons into consideration?

A further way to resist this pluralist response is to point out that it is the general structure of the problem that causes trouble for pluralism. The following represents the structure of the Gyges case I began with (let X and Y represent two normative domains and 1,2 and 3 represent the available courses of action):

Table 2. The Generic Concurrent Case

\begin{tabular}{|c|c|c|c|}
\hline & $\mathbf{1}$ & $\mathbf{2}$ & $\mathbf{3}$ \\
\hline $\mathbf{X}$ & $\operatorname{Bad}(-1,000)$ & $\operatorname{Good}(+1,000)$ & $\operatorname{Good}(+1,000)$ \\
\hline $\mathbf{Y}$ & $\operatorname{Good}(+1,000)$ & $\operatorname{Bad}(-1,000)$ & $\operatorname{Good}(+1,000)$ \\
\hline
\end{tabular}

We are in the dark about what normative domains $\mathrm{X}$ and $\mathrm{Y}$ are; we know only that they are genuine normative domains, not mere D-reasons. This assumes nothing that the restricted pluralist is not already committed to. Even at this level of generality, where our partisanships do not seem to be interfering, we can recognize that choosing 3 is, in some sense, a best. ${ }^{17}$ If asked which of these three actions one would recommend in this generic case, I suspect most people would choose 3. They may even add "obviously."

If our interlocutor were to reject the intuition that 3 is the best choice available, then we could press a further argument. The only difference between 1 and 3 is that 3 is good according to the standards of X, whereas 1 is bad by the standards of X. Likewise, the only difference between 2 and 3 is that 3 is good and 2 is bad, according to domain Y. So, in any pairwise comparison with one of its competitors, 3 is better in some normative domain, and is never worse in any respect. The following seems true:

17 For reasons that will be clear momentarily, I hesitate to describe 3 as the option that one "ought to" choose. 
Reason Principle. For any two courses of action, $\mathrm{A}$ and $\mathrm{B}$, if all of the reasons in favor of $A$ also count in favor of $B$, but not all of the reasons in favor of $B$ count in favor of $\mathrm{A}$, then $\mathrm{B}$ is the most reasonable course of action to take.

By the Reason Principle, 3 is the most reasonable action to take. Maybe "most reasonable choice" does not translate to "the choice that ought to be taken." Some think that "ought" implies obligation, whereas the "most reasonable choice" may be the best of many permissible options. Suppose, though, that we stipulate that the stakes are high, that the bad is very bad in that domain and the good is very good in that domain. With this stipulated, it seems correct to say that one ought to choose 3 with even the most fullthroated sense of "ought." After all, it seems right that one ought to choose the best option when there are no costs for doing so, and very high costs for failing to do so. It is especially reckless to make any suboptimal decisions when we do not know what the high costs are! Doing otherwise does not seem permissible.

I turn now to the pluralist's second line of defense, the claim that pluralism can accommodate the intuition that 3 is the best. The challenge is that, in Copp's Gyges case, self-interest and morality were stipulated to be the only normative domains in play; the "ought" that favors 3 appears to take both of these into account and issue a comprehensive and authoritative verdict. It appears, in other words, to be ought simpliciter. Sagdahl, as we have seen, has found a way to allow the pluralist to talk about "all things considered ought." But his quantificational interpretation of "all things considered ought" requires that all normative domains concur on a course of action; here, they concur only that 3 is among the best choices. So his account will not yield the result that Gyges ought to choose 3.

The best response for the pluralist, I think, would be to claim that Gyges both morally and self-interestedly ought to choose 3 . It is plausibly immoral to disregard one's own self-interest without justification. It is less obvious that one has a self-interested reason to be moral when there is no reason not to be, but one could defend a view of wellbeing according to which selfinterest and morality are entangled in this way, a possibility that Sagdahl considers (2014: 413-17). If that is right, then morality would not be indifferent to a choice between 1 and 3 , and neither would self-interest be indifferent to a choice between 2 and 3; both prefer 3. So there is no need to posit any ought simpliciter to account for our intuition. We can account for it fully given only the first-order normative domains that the pluralist accepts.

There are two problems with this response, however. It requires the pluralist to adopt controversial accounts of wellbeing and morality. It also fails to capture the intuitive force of the generic concurrent case. Intuitively, 3 is the most reasonable and, if the stakes are high enough, the one choice we ought to make. We know this without knowing anything about the content of domains $\mathrm{X}$ and $\mathrm{Y}$. So it seems to me that pluralism can neither adequately 
explain away the intuition that Gyges ought to choose 3 in my variation of the Gyges case, nor accommodate the sense of "ought" that it implies.

There remains one maneuver that the restricted pluralist can make to avoid the arguments that I have presented. Recall that the third criterion for normative pluralism was:

No authoritative adjudication: There is no "all things considered" domain capable of issuing verdicts about what one ought simpliciter to do; hence, no authority exists that is capable of adjudicating disputes between normative domains.

I have argued in this section that we should posit ought simpliciter to explain why, in both the concurrent Gyges case and the generic concurrent case, option 3 is intuitively best. If that is right, then this principle is false; it follows that normative pluralism, as we have been considering it until now, must also be false. But it does not rule out all forms of pluralism. It is possible to formulate the third criterion so that it is logically consistent with the existence of an "all things considered" domain and ought simpliciter. Consider:

No authoritative adjudication*: Whenever two or more normative domains issue conflicting recommendations, there is no one thing that ought simpliciter to be done.

If we modify pluralism so that this is its third criterion, then pluralism is logically consistent with the claim that we ought simpliciter to choose 3 in concurrence cases. If we accept this version of pluralism, and also accept ought simpliciter, then we arrive at what Dorsey calls "substantive pluralism" 18 and what David Phillips calls "permissive pluralism" (2011: 135). On that view, there is an all-things-considered domain, but it is indifferent between the choices in all cases of inter-domain conflict. In other words, whenever we encounter conflicts between domains, it is not irrational to take either choice. We can speak of both options being permissible so long as we do not read moral content into the word - either option is rationally permissible, or permissible from the all-things-considered perspective. This kind of pluralism is immune to the concurrence argument, but there appear to be independent reasons for rejecting it.

The primary problem for substantive pluralism, Dorsey argues, is that we have no reason for thinking that an all-things-considered domain would evaluate all options, in all conflict cases, as ties. If the version of substantive pluralism we are considering includes domains other than morality and selfinterest, then it is likely to seem to us that some domains are more important, all things considered, than others (e.g., morality seems much more important than etiquette). And, within domains, some courses of action come more strongly recommended than others (e.g., morality recommends "do not mur-

18 I am modifying Dorsey's terminology slightly here. His exact words are "substantive dualism" rather than "substantive pluralism" because he considers a version of pluralism in which only morality and self-interest are domains. 
der" versus "do not lie," but the former much more strongly). No explanation is forthcoming as to why all of these disparate options would be evaluated as ties from the perspective of Reason-as-such. Dorsey concludes that the most formidable version of pluralism is what he calls "structural pluralism," which denies that there is an all-things-considered domain, or ought simplicit$e r$, in the first place (2013: 117-27). So while the concurrent-cases objection is not decisive against all forms of pluralism, it is compelling against the most plausible form of pluralism.

\section{Conclusion}

I have argued that normative pluralism must be restricted and that restricted normative pluralism suffers from two problems: the sorting problem and the concurrent-case argument. The combined force of these two arguments, to my mind, justifies the conclusion that restricted pluralism is false. Hence, we should reject normative pluralism. Because pluralism includes the idea that one never ought simpliciter to do anything, its negation is compatible with our sometimes having irresolvable dilemmas. Our reasons may have, in Susan Wolf's words, "pockets of indeterminacy" (1994: 788). But the falsity of normative pluralism means that we are not forced to accept the conclusion that there is indeterminacy whenever we face a dilemma of this kind. The "cosmos of duty" may not be as orderly as we would like, but neither are they necessarily "reduced to a chaos" 19 as Sidgwick feared, by the possibility of inter-domain normative conflicts. ${ }^{20}$

Spencer Case

University of Colorado, Boulder

Department of Philosophy

casesj@colorado.edu

19 This famous and colorful line in the first edition of The Methods of Ethics was removed from subsequent editions. I quote it from Schneewind (1977: 352).

20 Thanks to Chris Heathwood, Alastair Norcross, Graham Oddie, Michael Huemer, Tyler Paytas, Jim Skidmore and the two anonymous referees for helpful feedback on earlier drafts of this paper. 


\section{References}

Baker, D. (forthcoming) "Skepticism About Ought Simpliciter," metaethicsworkshop.web. unc.edu/workshop-program.

Brink, D. O. (1997) "Kantian Rationalism: Inescapability, Authority and Supremacy," in G. Cullity and B. N. Gaut, eds., Ethics and Practical Reason, New York: Oxford University Press, pp. 255-92.

Chang, R. (1997) Incommensurability, Incompatibility and Practical Reason, Cambridge, MA: Harvard University Press.

Copp, D. (2009) "Toward a Pluralist and Teleological Theory of Normativity," Philosophy Issues 19(1): 21-37.

(2007) “The Wrong Answer to an Improper Question?” Canadian Journal of Philosophy 37(5): 97-130.

(1997) “The Ring of Gyges: Overridingness and the Unity of Reason," Social Philosophy and Policy 14(1): 86-106.

Dorsey, D. (2013) "Two Dualisms of Practical Reason," in R. Shafer-Landau, ed., Oxford Studies in Metaethics, Vol 8., New York: Oxford University Press, pp. 114-39.

Foot, P. (2002) "Rationality and Virtue," ch. 8 in her Moral Dilemmas and Other Topics in Moral Philosophy, New York: Oxford University Press, pp. 179-188. Originally (1994) Vienna Circle Institute Yearbook. 2, pp. 205-216.

Husi, S. (2013) "Why Reasons Skepticism Is Not Self-Defeating," European Journal of Philosophy 21(3): 424-49.

McLeod, O. (2001) "Just Plain 'Ought," The Journal of Ethics 5(4): 269-91.

Nagel, T. (1979) “The Fragmentation of Value,” Mortal Questions, New York: Cambridge University Press, pp. 128-41.

Parfit, D. (2011) On What Matters, New York: Oxford University Press.

Phillips, D. (2011) Sidgwickian Ethics, New York: Oxford University Press.

Plato (1997) The Republic, G. M. A. Grube, trans., in J. M. Cooper and D. S. Hutchinson, eds., Plato: Complete Works, Indianapolis, IN: Hackett Publishing Company.

Reid, T. (1969/1788) Essays on the Active Powers of the Human Mind, Cambridge, MA: MIT Press.

Sagdahl, M. S. (2014) "The Argument from Nominal-Notable Comparisons, 'Ought All Things Considered,' and Normative Pluralism,” The Journal of Ethics 18(4): 405-25.

Schneewind, J. B. (1977) Sidgwick's Ethics and Victorian Moral Philosophy, Oxford: Oxford University Press.

Scanlon, T. M. (1998) What We Owe to Each Other, Cambridge, MA: Harvard University Press.

Sidgwick, H. (1963/1874) The Methods of Ethics, 7th edition, London: Macmillan \& Co. Ltd.

Singer, P. (2010) The Life You Can Save: How to Do Your Part to End World Poverty, New York: Random House.

(1971) "Famine, Affluence, and Morality," Philosophy and Public Affairs 1(1): 229-43.

Slote, M. (1983) Goods and Virtues, Oxford: Clarendon Press.

Smith, M. (1994) The Moral Problem, Malden, MA: Blackwell Publishing.

Steinberg, D. I., Aung-Thwin, M. A. and Aung, M. H. (2016) "Myanmar: The Emergence of Nationalism," Encyclopedia Britannica Online, britannica.com/place/Myanmar/Theemergence-of-nationalism (accessed Sept. 1, 2016).

Stroud, S. (1998) "Moral Overridingness and Moral Theory," Pacific Philosophical Quarterly 79(2): 170-89.

Tiffany, E. (2007) "Deflationary Normative Pluralism," Canadian Journal of Philosophy. 37(5): 231-62.

Wolf, S. (1994) “Two Levels of Pluralism,” Ethics 102(4): 785-98. 